\title{
PENGARUH PERILAKU AGRESIF TERHADAP POTENSI KECELAKAAN PENGENDARA SEPEDA MOTOR REMAJA DENGAN STUDI KASUS PELAJAR SMA KOTA SURAKARTA
}

\author{
Dewi Handayani ${ }^{1}$ Dhony Eko Laksono ${ }^{2}$, dan Lydia Novitiana ${ }^{3}$ \\ ${ }^{1,3}$ Pengajar Program Studi Teknik Sipil, Universitas Sebelas Maret \\ Email: dewihandayani9@yahoo.com \\ ${ }^{2}$ Mahasiswa Program S1 Teknik Sipil Universitas Sebelas Maret \\ Email: dhonyekol@gmail.com \\ Jalan Ir.Sutami No.36A Surakarta 57126.Telp.0271647069. \\ Email:ydia_hidayati@yahoo.com
}

\begin{abstract}
The number of cases of accidents can be caused because the density of vehicles on the road as a result of the increasing number of motorists, especially motorcyclists, which often leads to aggressive behavior. Density often has an impact on humans, one of which is the emergence of aggressive behavior (Sarwono, 1995). This is because of aggressive action is the most common action that is displayed when in a solid state (Konecni, 1975, in Mann, et al, 1982). Aggressive driving is a behavior that planned to attack the physical, emotional or psychological environment or highway driving. Furthermore, Tasca (2000) adds that, aggressive driving committed intentionally, tend to increase the risk of accidents and motivated by impatience, annoyance, hostility, or an attempt to save time. Aggressive driving behavior is not always culminiting survived because based on the data that has been described, proved to be a lot of traffic accidents caused by aggressive driving behaviors. The aim of research to get characteristics of young motorcyclists and determine the effect of Aggressive Driving to accident potential on young motorcyclists. The research method using path analysis with AMOS 20.0 program. Collecting data using the questionnaire with Likert scale which given to respondents. The respondents consisted of 360 young motorcyclists who are high school students who are registered at the Educational Pioneers Safety School in Surakarta City. The results showed young motorcyclists in Surakarta City who have SIM C only 23.33\%. 94.44\% of teenagers had been riding a motorcycle before 17 years old Simultaneous effects of the potential effect of aggressive driving traffic accidents in young motorcyclists in Surakarta amounted to 68.60\%. Driving behavior holds an important role in traffic accident potential, it is needed a policy so the motorcyclist more orderly and obedient against the traffic rules.
\end{abstract}

Keywords: aggressive driving, accident, teenager, motorcycle

\begin{abstract}
ABSTRAK
Banyaknya kasus kecelakaan yang terjadi tersebut dapat disebabkan karena padatnya kendaraan yang ada di jalan sebagai akibat dari meningkatnya jumlah pengendara, terutama pengendara sepeda motor, yang seringkali menimbulkan tingkah laku agresif. Kepadatan seringkali memiliki dampak pada manusia, salah satunya yaitu timbulnya perilaku agresif (Sarwono, 1995). Hal ini dikarenakan tindakan agresif merupakan tindakan paling umum yang ditampilkan pada saat berada dalam kondisi padat (Konecni, 1975, dalam Mann, dkk, 1982). Aggressive driving adalah suatu perilaku yang direncanakan untuk menyerang secara fisik, emosi atau psikologi di lingkungan mengemudi atau jalan raya. Selanjutnya, Tasca (2000) menambahkan bahwa, aggressive driving dilakukan secara sengaja, cenderung meningkatkan risiko kecelakaan dan dimotivasi oleh ketidaksabaran, kekesalan, permusuhan, dan atau upaya untuk menghemat waktu. Perilaku aggressive driving tidak selamanya berujung selamat karena berdasarkan data yang relah diuraikan, terbukti banyak sekali kecelakaan lalu lintas yang disebabkan oleh perilaku aggressive driving. Tujuan penelitian untuk mengetahui karakteristik remaja pengendara sepeda motor dan mengetahui Pengaruh Perilaku Agresif (Aggressive Driving) Terhadap Potensi Kecelakaan Pengendara Sepeda Motor Remaja. Metode penelitian menggunakan analisis jalur dengan program AMOS 20.0. Pengumpulan data menggunakan kuisioner dengan skala likert yang diberikan kepada responden. Responden terdiri dari 360 remaja pengendara sepeda motor yang merupakan pelajar tingkat Sekolah Menengah Atas (SMA) yang terdaftar sebagai Sekolah Pelopor Keselamatan di Kota Surakarta. Hasil penelitian menunjukkan remaja pengendara sepeda motor di
\end{abstract}


Kota Surakarta yang memiliki SIM C hanya 23.33\%. Sebesar 94.44\% remaja telah mengendarai sepeda motor sebelum usia 17 tahun. Pengaruh simultan pengaruh berkendara agresif terhadap potensi kecelakaan lalu lintas pada remaja pengendara sepeda motor di Kota Surakarta adalah sebesar 68,60\%. Perilaku berkendara memegang peranan penting terhadap potensi kecelakaan lalu lintas sehingga diperlukan suatu kebijakan agar pengendara sepeda motor lebih tertib dan taat pada aturan lalu lintas.

Kata kunci: perilaku berkendara agresif, kecelakaan, remaja, sepeda motor

\section{PENDAHULUAN}

Meningkatnya kepadatan lalu lintas dan kurangnya kesadaran lalu lintas yang baik dari pengendara menyebabkan tingginya angka kecelakaan lalu lintas di Indonesia. WHO mencatat 1,25 juta orang meninggal setiap tahunnya dalam kecelakaan lalu lintas dan 50 juta orang korban kecelakaan lalu lintas mengalami luka serius maupun catat tetap. Kecelakaan lalu lintas jalan adalah penyebab utama kematian di kalangan anak muda, berusia 15 sampai 29 tahun, dan $73 \%$ adalah laki-laki (WHO, 2016). Banyaknya kasus kecelakaan yang terjadi tersebut dapat disebabkan karena padatnya kendaraan yang ada di jalan sebagai akibat dari meningkatnya jumlah pengendara, terutama pengendara sepeda motor, yang seringkali menimbulkan tingkah laku agresif. Kepadatan seringkali memiliki dampak pada manusia, salah satunya yaitu timbulnya perilaku agresif (Sarwono, 1995). Hal ini dikarenakan tindakan agresif merupakan tindakan paling umum yang ditampilkan pada saat berada dalam kondisi padat (Konecni, 1975, dalam Mann, dkk, 1982). Perilaku aggressive driving tidak selamanya berujung selamat karena berdasarkan data yang relah diuraikan, terbukti banyak sekali kecelakaan lalu lintas yang disebabkan oleh perilaku aggressive driving. Dari uraian di atas, maka sangat penting untuk mengadakan penelitian tentang Pengaruh Perilaku Agresif (Aggressive Driving) Terhadap Potensi Kecelakaan Pengendara Sepeda Motor Remaja dengan Studi Kasus Pelajar SMA Pelopor Keselamatan Kota Surakarta.

\section{LANDASAN TEORI}

Hasil penelitian Pardiningsih dan Thobagus (2014) menunjukkan Korelasi product moment dari Spearman menunjukkan korelasi sebesar $\mathrm{r}=0.331$ dan $\mathrm{p}=0.001(\mathrm{p}<0.01)$, yang artinya ada hubungan yang signifikan antara risk taking behavior dengan aggressive driving. Sumbangan efektif risk taking behavior terhadap aggressive driving yaitu sebesar $11 \%$.

Penelitian yang dilakukan oleh Utami (2010) dengan tujuan untuk melihat hubungan antara persepsi risiko kecelakaan dengan aggressive driving pengemudi remaja. Hasil penelitian menunjukkan terdapat hubungan yang signifikan antara persepsi resiko kecelakaan dengan aggressive driving pengemudi motor usia remaja. Hal ini berarti semakin tinggi persepsi resiko kecelakaan maka aggressive driving pengemudi remaja semakin rendah. Sebaliknya, semakin rendah persepsi resiko kecelakaan maka aggressive driving pengemudi remaja semakin tinggi

Dalam penelitian Darmawan (2015) dengan tujuan untuk mengetahui hubungan antara persepsi kesesakan di jalan raya dan jenis kelamin dengan aggressive driving menunjukkan bahwa terdapat perbedaan tingkat aggressive driving antara pengemudi laki-laki dan perempuan. Laki-laki lebih agresif pada saat mengemudi. Namun, hubungan persepsi kesesakan dengan aggressive driving lebih kuat terlihat pada subjek perempuan daripada laki-laki. Selain itu, tingkat agresivitas juga menunjukkan perbedaan berdasarkan usia. Pada usia 17 tahun, perilaku aggressive driving muncul lebih tinggi daripada usia lain.

Constantinou dkk (2011) meneliti Risky and aggressive driving in young adults: Personality matters. Hasil penelitian menunjukkan bahwa hasil dari korelasi dan SEM menggunakan AMOS 6 menunjukkan efek kepribadian langsung pada hasil mengemudi hanya sedikit sedangkan kepribadian memiliki korelasi yang signifikan dengan perilaku mengemudi menyimpang, menunjukkan kepribadian yang merupakan distal namun penting prediktor dari hasil mengemudi negatif. Sifat beresiko tinggi ini tampak di puncak antara pengemudi lelaki muda dengan demikian kepribadian penting dalam memahami agresfi dan beresiko mengemudi oleh orang dewasa muda dan perlu dipertimbangkan dalam merancang kebijakan pencegahan kecelakaan yang ditargetkan.

Hasil penelitian Septiningsih (2011) yang bertujuan untuk mendeskripsikan tingkat agresivitas berkendaraan/agressive driving di jalan raya pada peserta didik (remaja) Sekolah Menengah Kejuruan/SMK Muhammadiyah 2 Ajibarang. Hasil penelitian berupa deskripsi dari agresivitas berkendaraan sepeda motor yang dilakukan oleh peserta didik Sekolah Menengah Kejuruan/SMK Muhammadiyah 2 Ajibarang jurusan otomotif itu menggambarkan bahwa terdapat agresivitas pada semua peserta didik dalam berkendaraan di jalan raya. Agresivitas dalam mengendarai sepeda motor berbentuk agresif fisikal, yaitu melakukan penyerangan yang bersifat fisik 
misalkan memukul pengendara lain atau merusak kendaraannya, agresif gestural yaitu melakukan penyerangan yang ditunjukkan dengan gerakan-gerakan tubuh misalnya mengacungkan tangan/jari tangan dengan cara-cara tertentu untuk menghina atau merendahkan dan menghina orang lain, dan agresif verbal yaitu melakukan penyerangan yang ditunjukkan dengan ucapan-ucapan atau kata-kata umpatan kepada penyebrang jalan atau kepada pengendara lain.

\section{METODE PENELITIAN}

Penelitian ini menggunakan metode analisis jalur dengan bantuan program AMOS 20.0. Analisis Jalur (path analysis) adalah perluasan dari model regresi yang digunakan untuk menganalisis pola hubungan antar variabel dengan tujuan untuk mengetahui pengaruh langsung maupun tidak langsung dari himpunan variabel bebas (eksogen) terhadap variabel terikat (endogen) (Riduwan, 2012). Model merupakan analisis jalur satu arah dengan empat variabel bebas dan satu variabel terikat. Variabel bebas terdiri dari mengantuk, kecepatan tinggi, pelanggaran lampu dan rambu lalu lintas, dan perilaku berbahaya yang tidak lazim. Variabel terikat merupakan potensi kecelakaan lalu lintas.

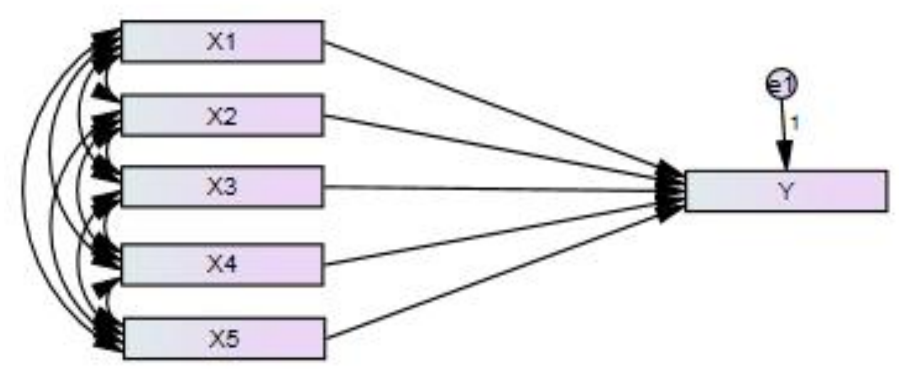

Gambar 1. Model Diagram Jalur Penelitian

$\mathrm{X}_{1}=$ Mengemudi dengan kecepatan tinggi yang kemudian menimbulkan tingkah laku membuntuti terlalu dekat dan berpindah jalur dengan kasar saat menyalip

$\mathrm{X}_{2} \quad=$ Menyalip dengan berpindah-pindah jalur secara zig-zag

$\mathrm{X}_{3}=$ Tidak memberikan celah dan menghalangi kepada pengemudi lain untuk menyalip, dan menerobos palang pintu kereta api

$\mathrm{X}_{4} \quad=$ Menyalip, Berbelok dan berpindah jalur tanpa menyalakan lampu sen

$\mathrm{X}_{5} \quad=$ Melanggar lampu merah untuk masuk ke jalur selanjutnya dan berpindah- $\quad$ pindah jalur

$\mathrm{Y} \quad=$ Potensi kecelakaan lalu lintas

Hipotesis awal persamaan struktural analisis jalur:

$\mathrm{Y}=\rho_{\mathrm{yx} 1} \mathrm{X}_{1}+\rho_{\mathrm{yx} 2} \mathrm{X}_{2}+\rho_{\mathrm{yx} 3} \mathrm{X}_{3}+\rho_{\mathrm{yx} 4} \mathrm{X}_{4}+\rho_{\mathrm{yx} 5} \mathrm{X}_{5}+\rho_{\mathrm{y}} \varepsilon \operatorname{dan} \mathrm{R}_{\mathrm{yx} 1 \times 2 \times 3 \times 4 \times 5 \times 6}^{2}$

Model tersebut akan diuji signifikansi parsial pengaruh variabel bebas terhadap variabel terikat. Dalam mengambil keputusan uji, digunakan derajat kemaknaan 0.05 dengan ketentuan bila $p$ value $<0.05$ maka variabel berpengaruh secara signifikan dan bila $p$ value $>0.05$ maka variabel tidak berpengaruh secara signifikan. Apabila dalam pengujian terdapat variabel bebas yang tidak berpengaruh signifikan terhadap variabel terikat, maka akan diberlakukan analisis jalur model trimming. Model trimming adalah model yang digunakan untuk memperbaiki suatu model struktur analisis jalur dengan cara mengeluarkan dari model variabel eksogen yang koefisien jalurnya tidak signifikan (Kusnendi, 2005 dalam Riduwan, 2012).

Data yang digunakan dalam penelitian ini meliputi data primer dan data sekunder. Data primer merupakan data hasil kuisioner yang diisi oleh responden. Kuisioner berisi pernyataan yang mencerminkan perilaku pelanggaran lalu lintas dalam berkendara sehari-hari. Data sekunder terdiri dari data lokasi dan data populasi yang diperoleh dari Kementrian Pendidikan dan Budaya. Populasi dalam penelitian ini adalah seluruh pelajar tingkat Sekolah Menengah Atas (SMA) yang terdaftar sebagai Sekolah Pelopor Keselamatan di Kota Surakarta. Peneliti menggunakan tabel dari Issac dan Michael untuk menentukan jumlah sampel dengan tingkat kesalahan 5\%. Pengumpulan data dengan menyebarkan kuisioner kepada 360 remaja pengendara sepeda motor.

\section{HASIL DAN PEMBAHASAN}

Pengumpulan data dalam penelitian ini dilaksanakan selama 23 hari yaitu pada tanggal 24 Agustus - 15 September 2016 dengan mengambil data dari responden penelitian yang telah ditentukan. Populasi dalam penelitian ini adalah 
seluruh pelajar tingkat Sekolah Menengah Atas (SMA) yang terdaftar sebagai Sekolah Pelopor Keselamatan di Kota Surakarta. Kuisioner diberikan pada responden yang terdiri dari 360 remaja pengendara sepeda motor. Penyebaran kuisioner didistribusikan sesuai populasi masing-masing sekolah.

\section{Karakteristik koresponden}

Karakteristik responden pada penelitian ini diuraikan berdasarkan usia, jenis kelamin, kepemilikan SIM C, usia saat pertama mengendarai sepeda motor, lama mengendarai sepeda motor. Berdasarkan hasil pengumpulan data, karakteristik mengenai komposisi responden diuraikan sebagai berikut.

\section{Karakteristik Responden Berdasarkan Usia}

Karakteristik responden berdasarkan usia responden dijelaskan dengan Tabel 1 berikut:

Tabel 4.1. Jumlah Responden Berdasarkan Usia

\begin{tabular}{|c|c|c|}
\hline Usia & Jumlah & Persentase \\
\hline 14 tahun & 1 & $0.28 \%$ \\
\hline 15 tahun & 48 & $13.33 \%$ \\
\hline 16 tahun & 84 & $23.33 \%$ \\
\hline 17 tahun & 174 & $48.33 \%$ \\
\hline 18 tahun & 51 & $14.17 \%$ \\
\hline 19 tahun & 1 & $0.28 \%$ \\
\hline 20 tahun & 1 & $0.28 \%$ \\
\hline Total & 360 & $100 \%$ \\
\hline
\end{tabular}

Dari tabel karakteristik responden berdasarkan usia diatas, didapatkan bahwa responden yang berusia 14 tahun sebanyak 1 orang $(0.28 \%)$, responden yang berusia 15 tahun sebanyak 48 orang (13.33\%), responden yang berusia 16 tahun sebanyak 84 orang (23.33\%), responden yang berusia 17 tahun sebanyak 174 orang $(48.33 \%), \%)$, responden yang berusia 18 tahun sebanyak 51 orang $(14.17 \%)$, responden yang berusia 19 tahun sebanyak 1 orang $(0.28 \%)$, dan responden yang berusia 20 tahun sebanyak 1 orang $(0.28 \%)$. Penelitian menunjukkan bahwa $36.94 \%$ pelajar yang berusia di bawah 17 tahun sudah mengendarai sepeda motor.

\section{Karakteristik Responden Berdasarkan Jenis Kelamin}

Jenis kelamin menjadi bahan pertimbangan terhadap interpretasi tingginya kecelakaan lalu lintas. Karakteristik responden berdasarkan jenis kelamin dijelaskan dengan Tabel 2.

Tabel 2. Jumlah Responden Berdasarkan Jenis Kelamin

\begin{tabular}{|l|r|r|}
\hline Jenis Kelamin & \multicolumn{1}{|c|}{ Jumlah } & \multicolumn{1}{c|}{ Persentase } \\
\hline Laki-laki & 174 & $48.33 \%$ \\
\hline Perempuan & 186 & $51.67 \%$ \\
\hline Total & 360 & $100 \%$ \\
\hline
\end{tabular}

Berdasarkan tabel diatas, karakteristik responden berdasarkan jenis kelamin terdistribusi hampir sama. Responden yang berjenis kelamin laki-laki adalah sebanyak 174 responden $(48.33 \%)$ dan responden yang berjenis kelamin perempuan sebanyak 186 responden $(51.67 \%)$.

\section{Karakteristik Responden Berdasarkan Kepemilikan SIM C}

Karakteristik responden berdasarkan kepemilikan SIM C dijelaskan pada Tabel 3.

Tabel 3. Karakteristik Responden Berdasarkan Kepemilikan SIM C 


\begin{tabular}{|l|c|c|}
\hline \multicolumn{1}{|c|}{ Kepemilikan SIM C } & Jumlah & Persentase \\
\hline Memiliki SIM C & 84 & 23.33 \\
\hline Tidak Memiliki SIM C & 276 & 76.67 \\
\hline Total & 180 & $100 \%$ \\
\hline
\end{tabular}

Berdasarkan tabel di atas, responden yang memiliki SIM C pada penelitian ini adalah sebanyak 84 responden (23.33\%) dan yang tidak memilik SIM C adalah sebanyak 276 responden (76.67\%). Penelitian menunjukkan bahwa banyak pelajar di Kota Surakarta yang menggunakan kendaraan sepeda motor tanpa memiliki SIM C.

\section{Karakteristik Responden Berdasarkan Lama Menggunakan sepeda motor}

Karakteristik responden berdasarkan lama menggunakan sepeda motor dijelaskan dengan tabel 4 berikut ini :

Tabel 4. Gambaran umum berdasarkan lama menggunakan sepeda motor

\begin{tabular}{|c|c|c|}
\hline Lama Menggunakan Sepeda Motor & Frekuensi & Persentase (\%) \\
\hline $0,5-4$ tahun & 317 & 88.06 \\
\hline $5-8$ tahun & 41 & 11.39 \\
\hline $9-13$ tahun & 2 & 0.56 \\
\hline Total & 100 & $100 \%$ \\
\hline
\end{tabular}

Berdasarkan tabel di atas, lamanya responden menggunakan sepeda motor terbagi menjadi dua kelompok, yaitu kelompok 0,5 - 4 tahun, kelompok $5-8$ tahun dan kelompok $9-13$ tahun. Dari 360 orang responden yang telah menggunakan sepeda motor dengan rentang waktu $0,5-4$ tahun yaitu sebanyak 317 orang $(88,06 \%)$, responden yang telah menggunakan sepeda motor dengan rentang waktu $5-8$ tahun sebanyak 41 orang $(11.39 \%)$ dan responden yang telah menggunakan sepeda motor dengan rentang waktu $9-13$ tahun sebanyak 2 orang $(0.56 \%)$.

\section{Pengaruh Perilaku Berkendara Agresif Terhadap Potensi Kecelakaan}

Besarnya pengaruh langsung dan tidak langsung varibel mengemudi dengan kecepatan tinggi yang kemudian menimbulkan tingkah laku membuntuti terlalu dekat dan berpindah jalur dengan kasar saat menyalip, menyalip dengan berpindah-pindah jalur secara zig-zag, tidak memberikan celah dan menghalangi kepada pengemudi lain untuk menyalip, dan menerobos palang pintu kereta api, menyalip, berbelok dan berpindah jalur tanpa menyalakan lampu sen, dan melanggar lampu merah untuk masuk ke jalur selanjutnya dan berpindah-pindah jalur dengan metode analisis jalur secara keseluruhan akan dirangkum dalam Tabel 4.13 sebagai berikut:

Tabel 5. Koefisien Jalur, Pengaruh Langsung, Pengaruh Tidak Langsung, dan Pengaruh Total Variabel Bebas Terhadap Variabel Terikat

\begin{tabular}{|c|c|c|c|c|}
\hline \multirow{2}{*}{ Variabel } & \multirow{2}{*}{$\begin{array}{c}\text { Koefisien } \\
\text { jalur }\end{array}$} & Langsung & Tidak Langsung & Total \\
\cline { 3 - 5 } & 0,224 & 5,02 & 11,91 & 16,93 \\
\hline $\mathrm{X}_{1}$ & 0,154 & 2,4 & 8,57 & 10,97 \\
\hline $\mathrm{X}_{2}$ & 0,242 & 5,86 & 12,22 & 18,08 \\
\hline $\mathrm{X}_{3}$ & 0,129 & 1,66 & 6,87 & 8,53 \\
\hline $\mathrm{X}_{4}$ & 0,185 & 3,42 & 10,67 & 14,09 \\
\hline $\mathrm{X}_{5}$ & \multicolumn{3}{|r}{ Total } & 68,6 \\
\hline
\end{tabular}

Besarnya kontribusi mengemudi dengan kecepatan tinggi yang kemudian menimbulkan tingkah laku membuntuti terlalu dekat dan berpindah jalur dengan kasar saat menyalip, menyalip dengan berpindah-pindah jalur secara zigzag, tidak memberikan celah kepada pengemudi lain dengan selalu memotong dengan jarak yang dekat dan menerobos palang pintu kereta api, menyalip, Berbelok dan berpindah jalur tanpa menyalakan lampu sen, melanggar lampu merah untuk masuk ke jalur selanjutnya dan berpindah-pindah jalur, dan menghalangi pengemudi lain untuk menyalip mempengaruhi potensi kecelakaan lalu lintas pada remaja pengendara sepeda motor di Kota Surakarta 
adalah $68,60 \%$.

Hasil penelitian ini sesuai dengan penelitian sebelumnya yang dilakukan oleh Tasca (2000) dimana Bentuk perilaku aggressive driving yang dijelaskan lebih mengarah pada perilaku mengemudi yang berbahaya dan dapat meningkatkan resiko kecelakaan. Hal ini dilihat dari hasil pengaruh total dari variabel-variabel aggressive driving yang diteliti bernilai kontribusi sebesar $68,6 \%$.

Dari penelitian yang dilakukan peneliti, variabel-variabel bebas yang ditinjau oleh peneliti masih dapat dikembangkan secara luas guna menemukan variabel-variabel lain yang memiliki pengaruh terhadap potensi kecelakaan dan dapat dianalisis dengan metode analisis lain yang lebih mendetail terhadap model.

Penelitian ini dilakukan dengan mengambil 360 sampel yang artinya hanya 4,75\% dari total pelajar pada sekolah yang dijadikan obyek penelitian yaitu 7565. Hasil analisis akan lebih baik jika sampel yang diambil lebih besar jumlahnya. Selanjutnya dalam metode pengambilan data masih dapat dikembangkan dengan menggunakan kuisioner online untuk menambah efisiensi waktu dan mempermudah dalam pengambilan data. Hasil dari penelitian menunjukkan masih kurangnya perhatian remaja terhadap lalu lintas maka perlu adanya kegiatan sosialisasi akan pentingnya peraturan lalu lintas.

\section{KESIMPULAN}

Kesimpulan yang dapat diambil dari penelitian adalah sebagai berikut:

a. Karakteristik remaja pengendara sepeda motor

1. Sebesar $94.44 \%$ remaja di Kota Surakarta telah mengendarai sepeda motor sebelum cukup usia.

2. Sebesar $76.77 \%$ remaja pengendara sepeda motor di Kota Surakarta tidak memiliki SIM C.

b. Pengaruh simultan perilaku berkendara agresif (Aggressive Driving) terhadap potensi kecelakaan pada remaja pengendara sepeda motor di Kota Surakarta adalah sebesar 68,60\%. Dengan pengaruh tiap masingmasing variabel sebagai berikut :

1. Mengemudi dengan kecepatan tinggi yang kemudian menimbulkan tingkah laku membuntuti terlalu dekat dan berpindah jalur dengan kasar saat menyalip mempengaruhi potensi kecelakaan sebesar $16,93 \%$.

2. Menyalip dengan berpindah-pindah jalur secara zig-zag mempengaruhi potensi kecelakaan sebesar $10,97 \%$.

3. Tidak memberikan celah dan menghalangi kepada pengemudi lain untuk menyalip, dan menerobos palang pintu kereta api mempengaruhi potensi kecelakaan sebesar 18,08\%.

4. Menyalip, Berbelok dan berpindah jalur tanpa menyalakan lampu sen mempengaruhi potensi kecelakaan sebesar $8,53 \%$.

5. Melanggar lampu merah untuk masuk ke jalur selanjutnya dan berpindah-pindah jalur mempengaruhi potensi kecelakaan sebesar $14,09 \%$.

\section{REKOMENDASI}

Selama melakukan penelitian banyak terdapat hal-hal yang perlu diperhatikan. Untuk itu perlu diberikan saran-saran untuk penelitian-penelitian selanjutnya dikemudian hari.

a. Saran untuk penelitian

1. Penelitian selanjutnya perlu dikembangkan lebih banyak variabel bebas mau pun menambahkan variabel intervening.

2. Pengembangan terhadap metode analisis yang digunakan, seperti pemodelan yang lebih mendetail terhadap model menggunakan model persamaan struktural (Structural Equation Modeling).

b. Saran untuk pelaksanaan

1. Penelitian selanjutnya perlu dikembangkan metode pengambilan data, seperti menciptakan kuisioner yang bersifat online menggunakan internet untuk mendapatkan hasil dari responden. Metode ini dapat mempersingkat waktu penelitian dan mendapatkan hasil yang lebih akurat.

2. Meningkatkan kegiatan sosialisasi akan pentingnya peraturan lalu lintas kepada pelajar dan masyarakat lewat sekolah, seminar, atau media massa. 


\section{DAFTAR PUSTAKA}

Constantinou dkk. 2011. "Risky and aggressive driving in young adults: Personality matters”. Journal University of Cyprus, Cyprus.

Darmawan, A. 2015. Hubungan Antara Persepsi Kesesakan (Crowding) di Jalan Raya dengan Aggressive Driving Pengemudi Sepeda Motor Remaja di Yogyakarta yang Dimoderatori oleh Jenis Kelamin. Skripsi Fakultas Psikologi Universitas Gadjah Mada Yogyakarta.

Mann, Leon, dkk. 1982. "A test between deindividuation and emergent norm theories of crowd aggression". Journal of Personality and Social Psychology 1982, Vol. 42, No. 2, 260-272.

Pardiningsih, Nopiyanti. Nu'man, Thobagus M. 2013. Hubungan Antara Risk Taking Behavior dengan Aggressive Driving. Skripsi Program Studi Psikologi. Fakultas Psikologi dan Ilmu Sosial Budaya. Universitas Islam Indonesia. Yogyakarta.

Riduwan dan Kuncoro, Engkos Achmad. 2008. Cara Menggunakan dan Memakai Analisis Jalur. Bandung : Alfabeta.

Sarwono, Sarlito Wirawan. 1995. Psikologi lingkungan. Jakarta : Grasindo.

Septiningsih, N dkk. 2011. Studi Deskriptif Tentang Aggressive Driving Sepeda Motor di Jalan Raya pada Peserta Didik Sekolah Menengah Kejuruan (Smk) Muhammadiyah 2 Ajibarang. Penelitian Universitas Muhammadiyah Purwokerto

Tasca, Leo. 2000. A review of the literature on aggressive driving research. Road User Safety Branch. Canada. Diambil dari http://www.aggressive. drivers.com/papers/tasca/tasca.pdf pada tanggal 9 April 2016.

Utami, Nadiyya. 2010. Hubungan Persepsi Risiko Kecelakaan Dengan Aggressive Driving Pengemudi Motor Remaja. Skripsi Psikologi. Fakultas Psikologi, Universitas Islam Negeri Syarif Hidayatullah. Jakarta

WHO. 2016. Road Traffic Injuries. http://www.who.int. Diakses tanggal 6 Juni 2016. 